\title{
Impact of Purslane (Portulaca oleracea L.) Leaves Extract to Enhance the Anti-oxidant Potential of Edible Oils during Heating
}

\author{
Niharika Shanker and Sukumar Debnath* \\ Department of Technology Scale-up CSIR-Central Food Technological Research Institute, Mysore-570 020, INDIA
}

\begin{abstract}
The present work deals/ reveals with the effect of purslane leaves extract on the stability of soybean oil during heating and the acceptability of oil after preparation of poori (an Indian fried bread) by frying and its sensory evaluation. The ethanolic purslane leaves extract was blended with soybean oil at three different concentrations such as, 500, 1000 and $1500 \mathrm{ppm}$ (T1, T2 and T3) and compared with control. The sample added with $100 \mathrm{ppm}$ TBHQ was used as a positive control. Assessment of antioxidant activity of the ethanolic extract of purslane leaves was carried out by the estimation of total phenolic content, loss of $\beta$ carotene and antioxidant activity. The heating $\left(173 \pm 2^{\circ} \mathrm{C}\right.$ for $24 \mathrm{~h} ; 8 \mathrm{~h}$ heating cycles per day) performance of soybean oil incorporated with purslane leaves extract was evaluated in terms of peroxide value, free fatty acid, total polar material and fatty acid composition. The thermal stability of the oils was evaluated using differential scanning calorimeter. The poori was prepared to check the acceptability of the oil. Results suggest that leaves extract of purslane $(1500 \mathrm{ppm})$ may be used for obtaining reasonable thermal stability of soybean oil with acceptable sensory characteristics of the product. Although TBHQ showed almost similar thermal stability with leaves extract of purslane $(1500 \mathrm{ppm})$, natural anti-oxidant is more preferred over synthetic anti-oxidant.
\end{abstract}

Key words: purslane leaf extract, TBHQ, anti-oxidant potential, edible oils

\section{Introduction}

Recently the interest in use of natural antioxidant has gained momentum as that natural antioxidants are safer and superior than processed / artificial ones. Many sources of natural antioxidants are present such as spices, herbs, tea leaves, oilseeds, cereals, cocoa beans, grains, fruits, vegetables, enzymes, proteins etc. Purslane leaf is a good plant source of nutritional benefits with high antioxidant properties. It is one of the richest green plant sources of omega-3 fatty acids ${ }^{1)}$. Purslane leaves function as a potent antioxidant in lipid systems. The oxidative reaction is responsible for rancid odors and flavors of fats and oils which reduce the nutritional quality of the foods. Oxidation reactions consist of auto-oxidation, photo-oxidation, enzymatic oxidation and ketonic oxidation, whereas auto-oxidation, in general, is the deterioration of quality during storage of edible oils. Auto-oxidation is the reaction between oxygen and unsaturated fatty acids via an auto-catalytic procedure consists of a free radical chain mechanism. This chain includes beginning, propagation, and termination reactions that could be cyclical once started:

Initiation: $\quad \mathrm{RH} \longrightarrow \mathrm{R} \cdot$

Propagation $\quad \mathrm{R} \cdot+\mathrm{O}_{2} \longrightarrow \mathrm{ROO} \cdot$
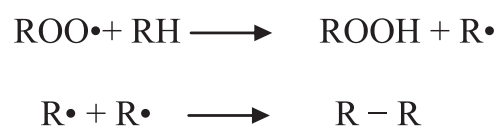

Termination $\mathrm{ROO} \bullet+\mathrm{R} \bullet \longrightarrow$ ROOR

$\mathrm{ROO} \bullet+\mathrm{ROO} \cdot \longrightarrow$ Non - radical products

In the beginning, free radicals are formed from the substrate. Antioxidants are components which stop auto-oxidation of oils and fats by giving their hydrogen to free radicals formed in the beginning and formulate the stages of auto-oxidation by following reactions $(\mathrm{AH}$ is antioxidant molecule):

\footnotetext{
* Correspondence to: Sukumar Debnath, Department of Technology Scale-up CSIR-Central Food Technological Research Institute, Mysore-570 020, INDIA

E-mail: debnath@cftri.res.in

Accepted January 16, 2019 (received for review June 30, 2018)

Journal of Oleo Science ISSN $1345-8957$ print / ISSN 1347-3352 online

http://www.jstage.jst.go.jp/browse/jos/ http://mc.manusriptcentral.com/jjocs
} 


\section{N. Shanker and S. Debnath}

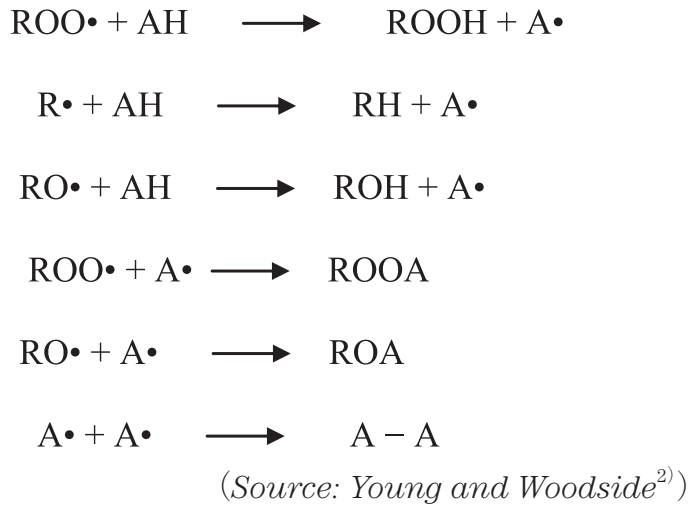

There are several variables which affect the auto-oxidation reaction such as unsaturation, temperature, the presence of oxygen, light, moisture, heavy metals and antioxidants. Antioxidants prevent free radical-induced cell and biological targets damage by preventing the formation of radicals, scavenging them, or by promoting their decomposition $^{2)}$. Usually, they can be classified as two main groups, natural and synthetic antioxidants. Among the synthetic types, the most frequently used are propyl gallate (PG) and tert-butyl hydroquinone (TBHQ). In most countries, the usage level of synthetic antioxidants is regulated and the safety of toxicity studies. Mainly the interest on naturally occurring antioxidants is developed because of the trend to minimize or avoid the use of synthetic food additives ${ }^{3)}$.

In recent years, phenolic compounds of plant origin have attracted considerable attention due to their beneficial functional and nutritional effects including antioxidant and antimicrobial activity ${ }^{4)}$. The literature on the use of natural plant extracts with antioxidant activities in various edible oils is scanty. This work has been done to reduce the application of synthetic compounds as antioxidants because of their harmful health effects. The present study concerns about the stabilization of oil with natural antioxidants during heating / frying. The calorimetric analysis is generally used to check the thermal stability of edible oils as thermal decomposition depends upon fatty acids composition and presence of antioxidants. The report on the antioxidant potential of purslane leaves extract for the stabilization of soybean oil during heating is scanty.

Poori is an Indian fried bread that is traditionally used during breakfast. It is made by deep frying of circular sheet prepared from the dough of wheat flour. Refined oil is used for the preparation of poori. The purpose of this research work was to explore the stability of antioxidant potential of purslane leaves extract towards heating stability of edible oils and sensory acceptability of the product (poori: an Indian fried bread) during frying.

\section{Materials and Methods 2.1 Materials}

Fresh leaves of purslane were procured from local market of Mysore. Refined soybean oil with no added antioxidant was procured from local market of Mysore, and was kept at $-20^{\circ} \mathrm{C}$ until analysis. All the chemicals and reagents procured from Sigma Aldrich, Bangalore, were of analytical grade. The solvents procured from Merck \& Co. (Darmstadt, Germany), were of analytical grade. All the experiments were done in triplicates.

\subsection{Preparation of leaf extract of purslane (LEP)}

The purslane leaves were dried under the shed at $30 \pm$ $2^{\circ} \mathrm{C}$ for 5 days. During solvent extraction method sample (dried purslane leaf, 10g) was mixed with $100 \mathrm{~mL}$ of solvent (Ethanol - water, 1:1, v/v). The solution was blended thoroughly in a shaker at $160 \mathrm{rpm}$ at room temperature for $48 \mathrm{~h}$. After extraction, the leaves extracts were filtered. The solvents were allowed to evaporate using a rotary evaporator (BUCHI, R-215, Switzerland) at $50^{\circ} \mathrm{C}$. The concentrated leaf extract was added into soybean oil (SBO) at three different concentrations; 500 ppm, 1000 ppm and 1500 ppm (T1, T2, and T3). These samples were compared with control(blank; with no addition of extract) and the positive control sample(Tertiary butylhydroquinone, TBHQ, $100 \mathrm{ppm}$ ). The samples filled in glass bottles were kept at room temperature for further analysis.

\subsection{Analysis of natural antioxidants}

The total phenolic content (TPC) of purslane leaf extract was expressed in terms of gallic acid by the method followed by Anwar et $a l{ }^{5)}$ The $\beta$-carotene was estimated by the method followed by Taga et $\mathrm{al}^{6}{ }^{6}$ In a flask $40 \mathrm{mg}$ of linoleic acid and $400 \mathrm{mg}$ of Tween 40 were added, about two milliliters of a solution of $\beta$-carotene in chloroform ( $1 \mathrm{mg} /$ $\mathrm{mL}$ ) was pipetted into it. Chloroform was evaporated using flash evaporator at $45^{\circ} \mathrm{C}$ for $4 \mathrm{~min}$. Distilled water $(100 \mathrm{~mL}$ ) was added gradually to the semisolid residue with vigorous shaking to form an emulsion. About 5-mL aliquot of the emulsion was added to a tube containing $0.2 \mathrm{~mL}$ of the antioxidant solution $(500 \mathrm{mg} / \mathrm{L})$. The absorbance of the same was recorded at $470 \mathrm{~nm}$ against the blank containing mixture without $\beta$-carotene. Tubes were placed in a water bath at $50 \pm 2{ }^{\circ} \mathrm{C}$, and the absorbance measurements were conducted again at 15-min intervals up to $120 \mathrm{~min}$. The 1-diphenyl-2-picrylhydrazyl radical (DPPH) was used for the determination of free radical-scavenging activity of the extracts $^{7)}$. Different concentrations of extract were added to an equal volume of ethanolic DPPH $(100 \mu \mathrm{M})$ solution. Absorbance was taken at $517 \mathrm{~nm}$ at room temperature after 15 min. 


\subsection{Determination of free fatty acids, peroxide value and total polar material}

The determination of free fatty acids (FFA) and peroxide value(PV) for oxidative stability were carried out by the $\mathrm{AOCS}^{8)}$. The thermo-oxidative degradation level of the oil was measured by the changes in total polar material (TPM). The TPM present in oils was measured by instrumental method (Fri-Check, bvba, Belgium) based on changes in viscosity of oil during heating ${ }^{9,10)}$.

\subsection{Determination of fatty acids composition}

Fatty acid methyl esters (FAMEs) were prepared based on standard IUPAC method ${ }^{11)}$ and analysed using gas chromatography (Shimadzu, 2010) equipped with FID using fused silica Rtx-2330 column(Restek made, $30 \mathrm{~m} \times 0.32$ $\mathrm{mm}$ ID and $0.20 \mu \mathrm{m}$ film thickness). Injector port and detector temperature were set up at 230 and $250^{\circ} \mathrm{C}$, respectively. The $\mathrm{N}_{2}$ was used as a carrier gas. Initially, column temperature was maintained at $120^{\circ} \mathrm{C}$, followed by increasing to $220^{\circ} \mathrm{C}$ in $20 \mathrm{~min}$, and holding the same for $10 \mathrm{~min}$. The fatty acids were identified by comparing their fragmentation pattern and retention time with authentic standards.

\subsection{Heating studies of oils}

The samples $(50 \mathrm{~g})$ of each variation were heated continuously in $100 \mathrm{~mL}$ beakers on a hot plate at $173 \pm 2^{\circ} \mathrm{C}$ for 24 $\mathrm{h}(8 \mathrm{~h} \text { heating cycles per day })^{12}$. The temperature was monitored using electronic temperature indicator (HTA, Bangalore). Samples of oil with extract and pure oil were taken for every $8 \mathrm{~h}$ heating cycle and kept in a refrigerator after cooling at room temperature for further analyses.

\subsection{Product formulation: preparation of poori}

The product is made by kneading the wheat flour $(1 \mathrm{~kg})$ with lukewarm water $(650 \mathrm{ml})$ in a Hobart mixer (Hobart, England) until the soft, non-sticky dough is formed, preparing equal sized $(0.02 \mathrm{~kg})$ balls from the dough, shaping the raw poori (av. dia. $0.08 \mathrm{~m}$, thickness $0.003 \mathrm{~m}$ ) using rolling board with rolling pin and frying the same. The frying was carried out at atmospheric pressure at $173 \pm 2^{\circ} \mathrm{C}$ for $5 \mathrm{~min}$ using laboratory scale deep-fat fryer(Mini Master Fryer, Continental, India) ${ }^{9)}$ with 21 oil. The temperature of the oil was measured by T-type thermocouple.

\subsection{Determination of melting temperature and enthalpy}

The melting temperature of the native oil and oils with LEP are determined at a specific heating / cooling rate using a differential scanning calorimeter (Perkin Elmer, USA ${ }^{13)}$. The heat flow and temperature were recorded and analyzed with in-built software.

\subsection{Sensory evaluation of the product}

Sensory evaluation of the product (poori) was carried out at our laboratory consists of booth room maintained at $22 \pm 2^{\circ} \mathrm{C}$ under fluorescent light. The samples of poori were randomly served to a panel of ten trained judges (coded with random number) who are regular consumer of similar food products. All the orders of servings were fully randomized. The prescribed method ${ }^{14)}$ of nine-point hedonic scale with sensory attributes such as appearance, taste, color, after taste, overall acceptance was followed for the sensory evaluation. Assessment of preferences coded with numerical values as extremely like (9), rather like(8), quite like (7), neither like nor dislike(6), dislike a little (5), rather dislike (4), dislike very much (3), highly dislike(2) and extremely dislike(1), was used for sensory evaluation.

\subsection{Statistical analysis}

All investigations were done in triplicates. The outcome was represented as mean \pm standard deviation. Data were statistically analyzed by ANOVA for comparison of means using Microsoft Excel 10 for significance $(p<0.05)$.

\section{Results and Discussion \\ 3.1 Accelerated oxidation studies}

The phenolic compounds are considered to be the most important phytochemicals responsible for antioxidant potential of plant materials. The purslane is a great source of ascorbic acid and flavonoids which also have the antioxidant activity. The polyphenolic compounds are broadly spread in different parts of the plants ${ }^{15}$. The study demonstrated that in many plant species, the total phenolic content and antioxidant activity are positively correlated with each other ${ }^{16)}$.

The Table 1 showed the ability of purslane leaf extracts to scavenge DPPH radical at concentrations of 500 to 1000 ppm and $1500 \mathrm{ppm}$ are. The result showed that scavenging-free radicals also increased till $1500 \mathrm{ppm}(41.6 \%$ to $87.1 \%$ ) which is due to an increase in concentration of total phenolic compounds (85.3 mg GAE/g to $151.7 \mathrm{mg} \mathrm{GAE} / \mathrm{g}$ ) (Table 1) in the extracts ${ }^{17}$. As the concentrations of phenolic compounds increases, the amount of hydroxyl groups present in the reaction medium is also increased. Consequently, chances of hydrogen donation to free radicals are increased ${ }^{18)}$. The outcome of the work revealed that LEP at maximum concentration of $1500 \mathrm{ppm}$ had the acceptable range.

The antioxidant activities of the purslane leaf extracts, measured by bleaching of $\beta$-carotene are indicated in Table 1. It is found that extract of purslane leaf at 500, 1000 and $1500 \mathrm{ppm}$ had the significant antioxidant activities. Therefore, LEP with different ratio was used to assess its effect on the stability of soybean oil during the heating process. 


\section{N. Shanker and S. Debnath}

Table 1 Antiradical activities, total phenol content and $\beta$-carotene assays of purslane leaf extracts.

\begin{tabular}{lcrrr}
\hline \multirow{2}{*}{ Parameter } & Control & \multicolumn{3}{c}{ Treatments } \\
\cline { 3 - 5 } & & T1 & T2 & T3 \\
\hline Antiradical Activity $(\%)$ & $38.4 \pm 0.1^{\mathrm{a}}$ & $41.6 \pm 0.4^{\mathrm{b}}$ & $70.8 \pm 0.9^{\mathrm{c}}$ & $87.1 \pm 0.6^{\mathrm{d}}$ \\
TPC Content $(\mathrm{mg} \mathrm{GAE} / \mathrm{g})$ & $85.3 \pm 0.4^{\mathrm{a}}$ & $91.3 \pm 0.3^{\mathrm{b}}$ & $134.04 \pm 0.2^{\mathrm{c}}$ & $151.7 \pm 0.2^{\mathrm{d}}$ \\
$\beta$ - Carotene $(\mu \mathrm{mol} / \mathrm{L})$ & $190 \pm 0.5^{\mathrm{a}}$ & $260 \pm 1.1^{\mathrm{b}}$ & $320 \pm 0.8^{\mathrm{c}}$ & $460 \pm 0.9^{\mathrm{d}}$ \\
\hline
\end{tabular}

where, T1, T2, T3: addition of natural antioxidant LEP at $500 \mathrm{ppm}, 1000 \mathrm{ppm}$ and 1500 ppm, respectively. Different letters within the same row in the respective tables indicate significant differences $(p<0.05)$. LEP-Leaf extract of purslane

\subsection{Effect of purslane leaves extract on fatty acid compo- sition}

Gas chromatography (GC) is a helpful methodical procedure to observe the effect of various heating conditions on the changes in the fatty acid composition of oils ${ }^{19)}$. The Table 2 (a, b) indicated the fatty acids composition of individual fatty acids of soybean oil and effect of heating on fatty acids profile. The fatty acid profile changes for all the oils with control, positive control with TBHQ and T3 (based on acceptability range). Many researchers ${ }^{20)}$ found that the

Table 2 (a) Fatty acid profile of individual fatty acids of soybean oil.

\begin{tabular}{lc}
\hline \multicolumn{1}{c}{ Fatty acids } & (\% relative area) \\
\hline Myristic acid & $0.5 \pm 0.1$ \\
Palmitic acid & $5.2 \pm 0.2$ \\
Stearic acid & $3.2 \pm 0.1$ \\
Oleic acid & $36.7 \pm 0.7$ \\
Linoleic acid & $46.0 \pm 0.4$ \\
Linolenic acid & $7.1 \pm 0.6$ \\
\hline
\end{tabular}

changes occur in fatty acids with two or three double bonds after the heat treatment is given to oils and fats. In the present study, the level of polyunsaturated fatty acid values (PUFA) was found to decrease the level of saturated fatty acids (SFA) was found to increase during heating. The estimated concentration of the unsaturated fatty acids showed that oil with TBHQ and with LEP had a good unsaturation level as compared to control oil. After $16 \mathrm{~h}$ of heating, unsaturation level was found to decrease more in all the oils in comparison to samples with added synthetic antioxidants. After $24 \mathrm{~h}$ the level of PUFA in control was found to significantly $(p<0.05)$ decrease from $53.1 \%$ to $33.8 \%$, in positive control $54.2 \%$ to $42.6 \%$, but less degraded from $53.1 \%$ to $40.4 \%$ in oil with the addition of extract(LEP 1500 PPM, T3). Similarly, the MUFA content was found to decrease in control $36.7 \%$ to $28.4 \%$, positive control $36.4 \%$ to $33.2 \%$ and in T3 $38.7 \%$ to $36.6 \%$. At the same time there is an increase in SFA in all the samples. After $24 \mathrm{~h}$ the SFA was observed in control 8.9\% to $28.3 \%$, positive control $8.8 \%$ to $19.5 \%$ and T3 $8.5 \%$ to $19.6 \%$.

\subsection{Effect of purslane leaves extract on free fatty acids}

The FFA is one of the markers of oil quality in the food

Table 2 (b) Fatty acid profile of SFA, MUFA and PUFA of fresh and heated oils.

\begin{tabular}{|c|c|c|c|c|c|c|c|c|c|}
\hline \multirow{3}{*}{$\begin{array}{l}\text { Duration of } \\
\text { heating }(\mathrm{h})\end{array}$} & \multicolumn{9}{|c|}{ Fatty acids profile (\% relative area) } \\
\hline & \multicolumn{3}{|c|}{ SFA } & \multicolumn{3}{|c|}{ MUFA } & \multicolumn{3}{|c|}{ PUFA } \\
\hline & Control & $\begin{array}{l}\text { Positive } \\
\text { Control }\end{array}$ & $\mathrm{T} 3$ & Control & $\begin{array}{l}\text { Positive } \\
\text { Control }\end{array}$ & $\mathrm{T} 3$ & Control & $\begin{array}{l}\text { Positive } \\
\text { Control }\end{array}$ & $\mathrm{T} 3$ \\
\hline 0 & $8.9 \pm 0.2^{\mathrm{a}}$ & $8.8 \pm 0.1^{\mathrm{a}}$ & $8.5 \pm 0.3^{\mathrm{a}}$ & $36.7 \pm 0.1^{\mathrm{b}}$ & $36.4 \pm 0.2^{\mathrm{b}}$ & $36.6 \pm 0.1^{\mathrm{b}}$ & $53.1 \pm 0.2^{\mathrm{c}}$ & $54.2 \pm 0.1^{\mathrm{d}}$ & $53.1 \pm 0.1^{\mathrm{c}}$ \\
\hline 8 & $14.8 \pm 0.3^{\mathrm{a}}$ & $12.1 \pm 0.1^{\mathrm{b}}$ & $18.7 \pm 0.2^{\mathrm{c}}$ & $34.1 \pm 0.5^{\mathrm{d}}$ & $35.2 \pm 0.1^{\mathrm{e}}$ & $34.5 \pm 0.2^{\mathrm{d}}$ & $48.7 \pm 0.3^{\mathrm{e}}$ & $51.8 \pm 0.2^{\mathrm{f}}$ & $50.8 \pm 0.1^{\mathrm{f}}$ \\
\hline 16 & $18.6 \pm 0.1^{\mathrm{a}}$ & $14.0 \pm 0.2^{\mathrm{b}}$ & $15.3 \pm 0.2^{\mathrm{c}}$ & $30.6 \pm 0.1^{\mathrm{d}}$ & $35.6 \pm 0.1^{\mathrm{e}}$ & $37.0 \pm 0.3^{\mathrm{f}}$ & $41.3 \pm 0.1^{\mathrm{g}}$ & $45.9 \pm 0.3^{\mathrm{h}}$ & $44.4 \pm 0.1^{\mathrm{i}}$ \\
\hline 24 & $28.3 \pm 0.1^{\mathrm{a}}$ & $19.5 \pm 0.1^{\mathrm{b}}$ & $19.6 \pm 0.1^{\mathrm{b}}$ & $28.4 \pm 0.3^{\mathrm{c}}$ & $33.3 \pm 0.1^{\mathrm{d}}$ & $38.7 \pm 0.1^{\mathrm{e}}$ & $33.8 \pm 0.2^{\mathrm{f}}$ & $42.6 \pm 0.1^{\mathrm{g}}$ & $40.4 \pm 0.2^{\mathrm{h}}$ \\
\hline
\end{tabular}

where, control: without adding any antioxidant; positive control: addition of synthetic anti-oxidant (TBHQ, 100ppm), T3: addition of natural antioxidant LEP at $1500 \mathrm{ppm}$. Different letters within the same row in the respective Tables (SFA, MUFA, PUFA) indicate significant differences $(p<0.05)$. LEP-Leaf extract of purslane, SFA-saturated fatty acids, MUFAmonounsaturated fatty acids, PUFA-polyunsaturated fatty acids. 


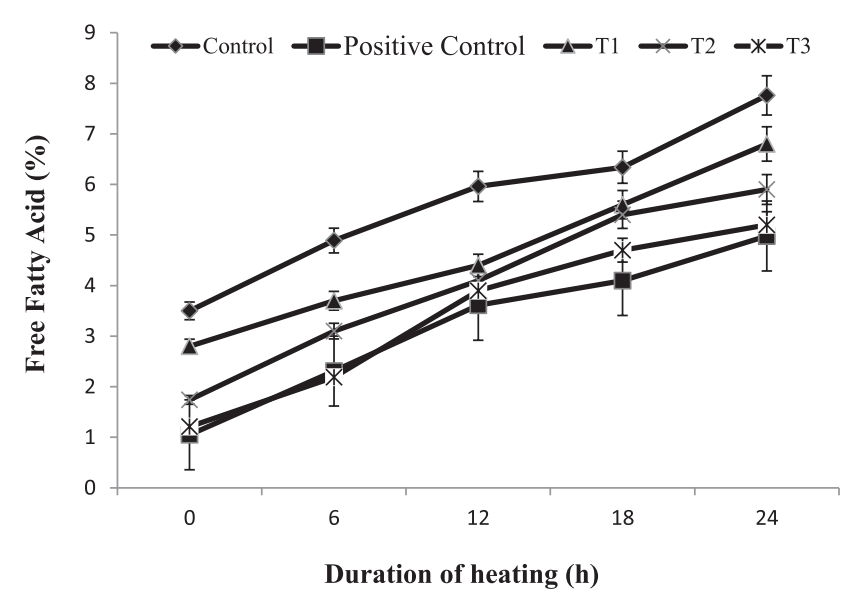

Fig. 1 Changes in free fatty acids of soybean oil during heating at $173 \pm 2^{\circ} \mathrm{C}$ for $24 \mathrm{hr}$. where, T1, T2, T3: addition of natural antioxidant LEP at $500 \mathrm{ppm}$, $1000 \mathrm{ppm}$ and $1500 \mathrm{ppm}$, respectively LEP-Leaf extract of purslane. Estimations were done in triplicates $(n=3)$. FFA values of control oil were found to be significantly $(p<0.05)$ different than oil samples treated with natural $(\mathrm{T} 1, \mathrm{~T} 2, \mathrm{~T} 3)$ and synthetic(TBHQ) antioxidants.

industry as it leads to the development of off-flavor in oils and fried foods. Changes in the FFA content of the oil samples are presented in Fig. 1. The FFA is a marker designed for estimation of oil degradation while heating/ frying $^{21)}$. The FFA showed an increasing trend during heating period to the end of the experiment in every sample ${ }^{22}$. The total FFA at the end of $24 \mathrm{~h}$ of heating for soybean oil containing (a) 500, (b) 1000 and (c) 1500 ppm of LEP, TBHQ, and SBO reached to 6.8, 5.9, 5.2, 4.9, and $7.7 \%$, respectively. However, the FFA values of control oil were found to be significantly $(p<0.05)$ higher than oil samples treated with natural and synthetic antioxidants. These results showed that natural antioxidants in LEP of $1000 \mathrm{ppm}$ and $1500 \mathrm{ppm}$ protected soybean oil from hydrolysis significantly similar to the synthetic antioxidants. During high-temperature heating of oils, the formation of FFA is due to the cleavage and oxidation of double bonds to form carbonyl compounds, which are subsequently oxidized to a low molecular weight of fatty acid ${ }^{23)}$. In the present study where the oil is heated in absence of water/ moisture, the hydrolysis of glycerides is negligible and the increase in FFA content is mainly due to oxidation.

\subsection{Effect of purslane leaves extract on peroxide value}

Changes in PV of the oil samples during the heating process at $173 \pm 2^{\circ} \mathrm{C}$ are shown in Fig. 2. The PV of control is reported to be $<2$ meq $\mathrm{O}_{2} / \mathrm{kg}^{24)}$. It was noticed that the extract is responsible for the significant $(p<0.05)$ reduction of $\mathrm{PV}$ of oils as compared to control oil. Initially, during heating, $\mathrm{PV}$ of $\mathrm{SBO}$ is observed to rise from 0 to $18 \mathrm{~h}$, for

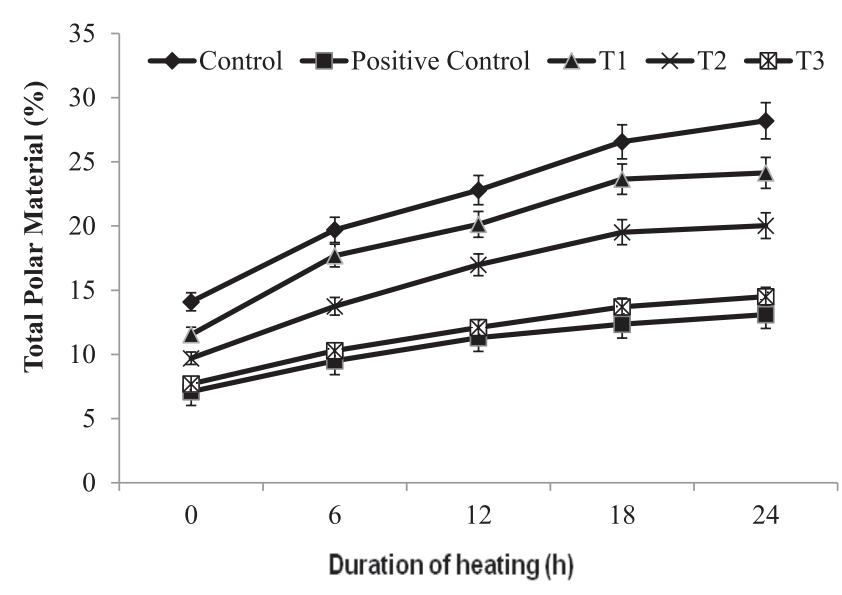

Fig. 2 Changes in per oxide value of soybean oil during heating at $173 \pm 2^{\circ} \mathrm{C}$ for $24 \mathrm{hr}$. where, T1, T2, T3: addition of natural antioxidant LEP at $500 \mathrm{ppm}$, $1000 \mathrm{ppm}$ and1500 ppm, respectively LEP-Leaf extract of purslane. Estimations were done in triplicates $(n=3)$. TPM values of control oil were found to be significantly $(p<0.05)$ different than oil samples treated with natural (T1, T2, T3) and synthetic (TBHQ) antioxidants.

TBHQ, for LEP at 1000 and $1500 \mathrm{ppm}$ from 0 to $12 \mathrm{~h}$ and reduced later on. Results of $\mathrm{PV}$ with peak value were shown as: TBHQ (1.4 meq $\mathrm{O}_{2} / \mathrm{kg}$ after $\left.12 \mathrm{~h}\right)$, LEP at 500 ppm (2.9 meq $\mathrm{O}_{2} / \mathrm{kg}$ after $\left.12 \mathrm{~h}\right)$, LEP at $1000 \mathrm{ppm}(1.87$ meq $\mathrm{O}_{2} / \mathrm{kg}$ after $\left.18 \mathrm{~h}\right), \mathrm{LEP}$ at $1500 \mathrm{ppm}\left(1.67 \mathrm{meq} \mathrm{O}_{2} / \mathrm{kg}\right.$ after $12 \mathrm{~h})$, and $\mathrm{SBO}\left(4.1 \mathrm{meq} \mathrm{O}_{2} / \mathrm{kg}\right.$ after $\left.12 \mathrm{~h}\right)$. This trend was corroborated with the previous study ${ }^{25}$. The rapid rise in PV of control oil showed that it is more susceptible to oxidation and degradation as well. While oils with 500, $1000,1500 \mathrm{ppm}$ of LEP and positive control indicated greater ability to prevent an increase of PV as compared to the other oil samples. The only analysis of PV is not a convincing factor to evaluate oils' oxidative changes while the heating / deep frying method, as peroxidase under frying conditions is unstable and get changed into further compounds such as carbonyl and aldehyde that cause PV abatement ${ }^{24)}$.

\subsection{Effect of purslane leaves extract oil stability}

Determination of total polar material(TPM) is one of the main tests and a suitable standard method to examine the thermal oxidative deterioration of the oils during heating / frying. Oil breaks down to generate hydroperoxides, acids and other free radicals, which may further cause polar molecules $^{26)}$. This experiment helps to find out the level of polar, oxidized components in a sample. Faster rate of formation of polar components is a cumulative indication of degradation of oil. Figure 3 showed changes in TPM content of the oil samples during the deep frying process. In many European countries, the TPM value is used as a 


\section{N. Shanker and S. Debnath}

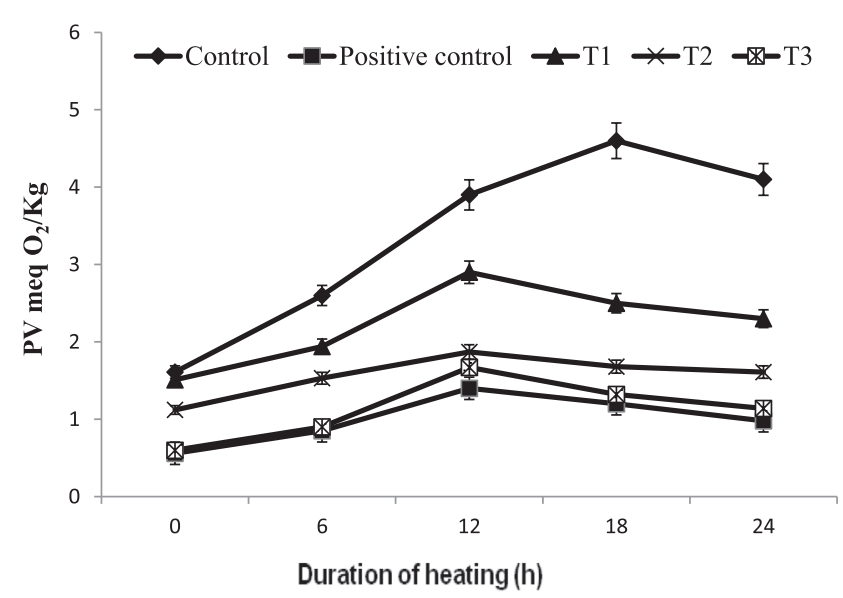

Fig. 3 Changes in total polar material of soybean oil during heating at $173 \pm 2{ }^{\circ} \mathrm{C}$ for $24 \mathrm{hr}$. where, T1, T2, T3: addition of natural antioxidant LEP at 500 ppm, 1000 ppm and 1500 ppm, respectively LEPLeaf extract of purslane. Estimations were done in triplicates $(n=3)$. PV values of control oil were found to be significantly $(p<0.05)$ different than oil samples treated with natural (T1, T2, T3) and synthetic (TBHQ) antioxidants.

marker for major oil degradation and it is adequate at maximum of $25-27 \%$ for used frying oil ${ }^{21)}$. The fresh soybean oil had a TPM content of $5.6 \%$, reflecting the good quality of the oil used, as TPM content of unused oils normally ranges between $0.4 \%-6.4 \%{ }^{27)}$. The TPM was found to increase during frying and had high correlation coefficient with heating time ${ }^{28}$. The TPM of the oils containing LEP of 500 and 1000 ppm and 1500 ppm, TBHQ and SBO after $24 \mathrm{~h}$ of frying were found to be $24.14,20.03,14.5$, 13.1 , and $28.2 \%$, respectively. This may be due to the increase in viscosity during frying/heating. These results showed that SBO reached beyond 25\% TPM(degradation limit for regulation purposes)after $24 \mathrm{~h}$ of heating. Therefore, the thermo-oxidative stability of soybean oil was observed to improve considerably in the presence of LEP and synthetic antioxidant as compared to control oil. The study is supported with the earlier work in which stability of the oil was influenced with the antioxidant effect of rosemary extract additives ${ }^{29)}$.

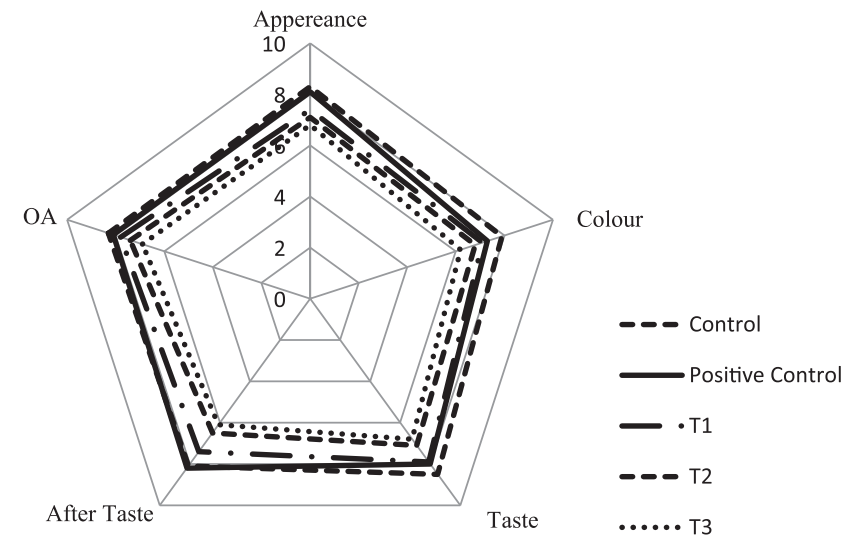

Fig. 4 Sensory attributes of poori at various concentrations of the leaf extract of purslane. where, T1, T2, T3: addition of natural antioxidant LEP at 500 ppm, 1000 ppm and 1500 ppm, respectively.

\subsection{Melting profiles of soybean oils containing TBHQ and LEP}

The melting profile of the control oil, positive control oil and the oil enriched with $\operatorname{LEP}(1500 \mathrm{ppm})$ after heating for a period of $24 \mathrm{~h}$ showed a single melting peak $\left(-9.4^{\circ} \mathrm{C}, \Delta \mathrm{H}\right.$ $1.2 \mathrm{j} / \mathrm{g} ; 1.8^{\circ} \mathrm{C}, \Delta \mathrm{H} 10.3 \mathrm{j} / \mathrm{g}$; and $-3.1^{\circ} \mathrm{C}, \Delta \mathrm{H}-\mathrm{j} / 1.7 \mathrm{~g}$, respectively) (Table 3 ). The reason could be due to the presence of higher levels of unsaturated fatty acids ${ }^{13)}$. However, it is observed that the enthalpy $(-1.7 \mathrm{~J} / \mathrm{g})$ for the oil with LEP was found to decrease in comparison to the enthalpy $(1.2 \mathrm{~J} / \mathrm{g})$ of control oil. This could be due to the lower degradation of the oil with $\operatorname{LEP}(1500 \mathrm{ppm})$ with the formation of lower amount of saturated fatty acids (19.6\%) as compared to control oil (28.3\%) during heating.

\subsection{Sensory evaluation of the product}

The results of the sensory evaluation of poori obtained by frying using SBO with different concentrations of LEP as adjudged by a panel of ten trained judges are shown in Fig. 4. Addition of LEP up to T2 (1000 ppm) level did not have any adverse result on taste, smell and color value. However, when the addition level was found to increase up to T3 level (1500 ppm), the sensory scores of these parameters showed no significant $(p>0.05)$ differences. Some of the panelists have observed for T3 having phenolic smell and taste, which resulted in lower smell and taste scores.

Table 3 Melting Temperature and enthalpy of native oil and oil with LEP.

\begin{tabular}{lcccc}
\hline \multicolumn{1}{c}{ Sample } & Onset $\left({ }^{\circ} \mathrm{C}\right)$ & Peak $\left({ }^{\circ} \mathrm{C}\right)$ & End set $\left({ }^{\circ} \mathrm{C}\right)$ & $\begin{array}{r}\text { Enthalpy } \\
(\Delta \mathrm{H}, \mathrm{j} / \mathrm{g})\end{array}$ \\
\hline Control oil & -19.2 & -9.4 & 2.5 & 1.2 \\
Oil heated upto 24 h with TBHQ & -8.7 & 1.8 & 9.1 & 10.3 \\
Oil heated upto 24 $\mathrm{h}$ with LEP $(1500 \mathrm{ppm})$ & -14.6 & -3.1 & -1.0 & -1.7 \\
\hline
\end{tabular}

where, LEP-Leaf extract of purslane, TBHQ- Tertiary butylhydroquinone 
The reason for the low colour score of T3 was due to the dark green color of LEP which has a slight but definite effect on this parameter.

\section{Conclusion}

Food processing operations require antioxidants that can sustain high temperatures during baking, cooking or frying, and provide protection to finished products. The ethanolic extract of purslane leaves showed an excellent antioxidant activity in soybean oil in a dose-dependent manner during accelerated oxidation during heating. The strong antioxidant activity of LEP in soybean oil was emphasized on the presence of potent anti-oxidative compounds with high thermal stability. Thus, the extract of purslane leaves can be used as an alternative source of natural antioxidants for increasing the stability of oils and oil-containing foods. Therefore, this study showed that the purslane has a good potential to be explored as a source of natural antioxidant.

\section{Acknowledgements}

The authors thank the Director, CSIR-CFTRI, Mysore, for providing infrastructure, constant encouragement and support. The authors also thank the Head, Department of Technology Scale-up, CSIR-CFTRI, Mysore, for his help and support. The first author gratefully acknowledges U.G.C for providing the financial assistance to carry out the present investigation.

\section{References}

1) Omara-Alwala, T.R.; Mebrahtu, T.; Prior, D.E.; Ezekwe, M.O. Omega-three fatty acids in purslane (Portulacaoleracea) tissues. J. Am. Oil Chem. Soc. 68, 198-199 (1991).

2) Young, I.S.; Woodside, J.V. Antioxidants in health and disease. J. Clin. Patholology. 54, 176-186 (2001).

3) Shahidi, F. Bailey's industrial oil and fat products. $6^{\text {th }}$ ed. John Wiley \& Sons, New Jersey (2005).

4) Bubonja-Sonje, M.; Giacometti, J.; Abram, M. Antioxidant and antilisterial activity of olive oil, cocoa and rosemary extract polyphenols. Food Chem. 127, 1821-1827(2011).

5) Anwar, F.; Siddiq, A.; Iqbal, S.; Asi, M.R. Stabilization of sunflower oil with Moringa oleifera leaves under ambient storage. J. Food Lipids 14, 35-49 (2007).

6) Taga, M.S.; Miller, E.E.; Pratt, D.E. Chia seeds as a source of natural lipid antioxidants. J. Am. Oil Chem. Soc. 61, 928-931 (1984).
7) Koleva, II.; Van Beek, T.A.; Linssen, J.P.H.; de Groot, A.; Evstatieva, L.N. Screening of plant extracts for antioxidant activity: a comparative study on three testing methods. Phytochem. Anal. 13, 8-17 (2002).

8) American Oil Chemists Society (AOCS). Official Methods and Recommended Practices of the American Oil Chemists Society AOCS. $7^{\text {th }}$ ed. Press Champaign IL, USA (2000).

9) Debnath, S.; Rastogi, N.K.; Gopala Krishna, A.G.; Lokesh, B.R. Effect of frying cycles on physical, chemical and heat transfer quality of rice bran oil during deep-fat frying of poori: An Indian traditional fried food. Food Bioprod. Process 90, 249-256 (2012).

10) Gertz, C. Chemical and physical parameters as a quality indicator of used frying fat. Sponsored by the German Society for Fat Research, Deutsche Gasellchachaft fur Fettewissenchaft(DGF), Hagen-Westfalia, Germany (March 20-21) (2000).

11) IUPAC. Standard Methods for the Analysis of Oils, Fats and Derivatives. $7^{\text {th }}$ ed. Blackwell Scientific Publication, Oxford, USA (1987).

12) Allam, S.S.M.; Mohamed, H.M.A. Thermal stability of some commercial natural and synthetic antioxidants and their mixtures. J. Food Lipids 9, 277-293(2002).

13) Debnath, S.; Raghavarao, K.S.M.S.; Lokesh, B.R. Hydrodynamic, thermo-analytical and molecular structural investigations of enzyme interesterified oil and its thermo-oxidative stability by thermo gravimetric analysis. J. Food Eng. 105, 671-679 (2011).

14) Poste, M.L.; Mackie, D.A.; Butler, G.; Larmond, E. Laboratory Methods for Sensory Evaluation of Foods. Research Branch, Canada, Department of Agriculture, Ottawa Publications (1987).

15) Katalinic, V.S.S.; Mozina, I.; Generalic, D.; Skroza, I.; Ljubenkov, A.; Klancnik. Phenolic profile, antioxidant capacity, and antimicrobial activity of leaf extracts from six Vitisvinifera L. varieties. Int. J. Food Prop. 16, 45-60 (2013).

16) Aladedunye, F.; Przybylski, R. Frying stability of high oleic sunflower oils as affected by composition of tocopherol isomers and linoleic acid content. Food Chem. 141, 2373-2378(2013).

17) Akkol, E.K.; Orhan, I.E.; Yesilada, E. Anticholinesterase and antioxidant effects of the ethanol extract, ethanol fractions and isolated flavonoids from Cistus laurifolius L. leaves. Food Chem. 131, 626-631 (2012).

18) Rajaei, A.; Barzegar. M.; Mobarez, A.M.; Sahari, M.A.; Esfahani, Z.H. Antioxidant, anti-microbial and antimutagenicity activities of pistachio (Pistachiavera) green hull extract. Food Chem. Toxicol. 48, 107-112 (2010).

19) Kowalski, R. GC analysis of changes in the fatty acid composition of sunflower and olive oils heated with quercetin, caffeic acid, protocatechuic acid. Acta 
Chromatogr. 18, 15-23(2007).

20) Jorge, N.; Gongalves, L.Ap.G.; Dobarganes, M.C. Influence of fatty acid composition on the formation of polar glycerides and polar fatty acids in sunflower oils heated at frying temperatures. Grasas y Aceites 48, 17-24 (1997).

21) Abdulkarim, S.M.; Long, K.; Lai, O.M.; Muhammad, S.K.S.; Ghazali, H.M. Frying quality and stability of high-oleic Moringa oleifera seed oil in comparison with other vegetable oils. Food Chem. 105, 1382-1389 (2007).

22) Wang, Y.; Chen, X.; Zhang, Y.; Chen, X. Antioxidant activities and major anthocyanins of myrobalan plum (Prunus cerasifera Ehrh.). J. Food Sci. 77, 388-393 (2012).

23) Latha, R.B.; Nasirullah, D.R. Physico-chemical changes in rice bran oil during heating at frying temperature. $J$. Food Sci. Technol. 51, 335-340 (2014).

24) Sulieman, A.E.R.M.; El-Makhzangy, A.; Ramadan, M.F. Antiradical performance and physicochemical characteristics of vegetable oils upon frying of French fries: a preliminary comparative study. J. Food Lipids 13,
259-276 (2006).

25) Farhoosh. R.; Khodaparast, M.H.H.; Sharif, A.; Rafiee, S. Olive oil oxidation: rejection points in terms of polar, conjugated diene, and carbonyl values. Food Chem. 131, 1385-1390 (2012).

26) Stier, R.F. Ensuring the health and safety of fried foods. Eur. J. Lipid Sci. Technol. 115, 956-964 (2013).

27) Delfanian, M.; Kenari, E.R.; Sahari, M.A. Frying stability of sunflower oil blended with jujube (Ziziphus mauritiana Lam.) leaf extract. Food Sci. Nutri. 3, 548-556 (2015).

28) Osawa, C.C.; Goncalves, L.A.G.; Gumerato, H.F.; Mendes, F.M. Study of the effectiveness of quick tests based on physical properties for the evaluation of used frying oil. Food Control 26, 525-530 (2012).

29) Vicente, G.; Martin, D.; Garcia-Risco, M.R.; Fornari, T.; Reglero, G. Supercritical carbon dioxide extraction of antioxidants from rosemary (Rosmarinus officinalis) leaves for use in edible vegetable oils. J. Oleo Sci. 61, 689-697 (2012). 